\title{
Um modelo de usina hidrelétrica como ferramenta no ensino de Física+*
}

Jonny Nelson Teixeira ${ }^{1}$

Departamento de Licenciatura em Física

Instituto Federal de São Paulo

Itapetininga - SP

Mikiya Muramatsu ${ }^{2}$

Instituto de Física - Universidade de São Paulo

São Paulo - SP

Luis Augusto Alves ${ }^{3}$

Instituto Federal de São Paulo

São Paulo - SP

\section{Resumo}

No atual contexto da sustentabilidade e do uso consciente de energia elétrica, preocupações com quedas no suprimento de energia e manifestações ambientais contra a construção de usinas cujo impacto ambiental é iminente, discussões sobre a produção de energia limpa e sustentável se tornam comuns nas escolas de ensino básico do país. Além disso, o conhecimento sobre a matriz energética no Brasil tem se intensificado sobretudo nas escolas de Ensino Básico, sem, contudo, propor uma discussão dos conceitos físicos importantes para a conservação de energia ocorrida nestes tipos de usinas. Muitos materiais impressos, como livros didáticos e apostilas, trazem discussões mais consistentes sobre os conceitos de eletromagnetismo, esquecendo-se de outros como de hidrodinâmica e energia mecânica. Este trabalho tem como objetivo apresentar uma proposta de construção de um modelo interativo de usina hidroelétrica com materiais recicláveis e de baixo custo, que pode ser utilizado para trabalhar

\footnotetext{
${ }^{+}$A model of hydroelectric power plant as a tool in the teaching of Physics

* Recebido: fevereiro de 2016.

Aceito: agosto de 2016.

${ }^{1}$ E-mail: jonny@if.usp.br

2 E-mail: mmuramat@if.usp.br

3 E-mail: Luis_aa@ig.com.br
} 
vários conceitos de mecânica rotacional, mecânica dos fluidos e eletromagnetismo em uma classe de Ensino Fundamental e Médio, de forma qualitativa, evidenciando os conceitos físicos envolvidos, seus fundamentos e interpretações.

Palavras-chave: Energia elétrica; Usina hidrelétrica; Ensino de Física; Eletromagnetismo.

\begin{abstract}
In the current context of sustainability and conscientious use of electric energy, concerns about electrical black-outs and environmental protests against the building of power plants whose environmental impacts are imminent, discussions about clean and sustainable energy become common in regular schools. In addition, the knowledge on the energy matrix in Brazil was intensified especially in basic education schools, without, however, to propose a discussion of important physical concepts for energy conservation that took place in these types of plants. Many printed materials such as textbooks and handouts, bring more consistent discussions on the concepts of electromagnetism, putting aside others as hydrodynamic and mechanical power. This paper aims to present a proposal to build a interactive hydroelectric plant model with recycled and low cost materials, which can be used to work several concepts of rotational mechanics, fluid mechanics and electromagnetism in a class of elementary and high school, in qualitative form, evidencing the physical concepts, their fundaments and interpretations.
\end{abstract}

Keywords: Electric energy; Power hydroelectric plant; Physics teaching; Electromagnetism.

\title{
I. Introdução
}

Geração e gasto de energia são assuntos geralmente tratados no terceiro ano do Ensino Médio e no Ensino Fundamental. No entanto, quando acontece, são geralmente propostos experimentos isolados, que tratam apenas de indução eletromagnética, como se o fenômeno fosse o único responsável pela energia elétrica que chega às casas dos alunos.

Numa época onde o ensino interdisciplinar é almejado e recomendado pelos órgãos governamentais que regularizam o ensino, ainda se veem baixos níveis no ensino de Ciências, 
como mostram alguns indicadores nacionais e internacionais (ENEM, 2008; PISA, 2006). Geralmente questões formuladas por estes indicadores exigem que o aluno tenha uma visão abrangente, reflexiva e, hoje, social sobre estes assuntos.

Assim, os alunos devem ter conhecimentos sobre como a energia elétrica é gerada, distribuída e gasta, não só para entender como e por que os fenômenos de indução eletromagnética acontecem, mas também para entender o processo de transformação das energias envolvidas na geração, iniciadas principalmente pela energia cinética, seja de transporte de massas de água nas usinas hidroelétricas, vento nas usinas eólicas ou devido à energia térmica que aumenta a energia cinética das moléculas de um gás, no caso das termoelétricas.

Entretanto, embora existam vários tipos de usinas, grande parte delas utiliza o mesmo tipo de gerador (eletromecânico), onde a única diferença está no elemento que faz a turbina girar. Conhecer os tipos de usina e a forma de geração pode fazer o aluno refletir, por exemplo, sobre a implantação de certos tipos de usinas geradoras no país e até mesmo opinar sobre o tema, ações que o faz exercer sua cidadania, o que acontece apenas se o seu nível de alfabetização científica for significativo. (TEIXEIRA, 2007; HAZEN; TREFIL, 2003; CHASSOT, 2000).

O objetivo principal deste trabalho é propor a construção de um experimento demonstrativo e interativo que ilustra o funcionamento de uma usina hidroelétrica, onde a energia cinética da água provém da pressurização de ar numa garrafa PET. Este tipo de trabalho, quando produzido pelos alunos, tem grande potencial para fomentar a discussão não apenas do funcionamento da usina em si, mas também dos fenômenos físicos envolvidos desde a energia primária e suas transformações na geração de energia elétrica.

Neste contexto, primeiramente será apresentada uma discussão sobre os fenômenos físicos envolvidos no processo de geração de energia desse modelo, desde a pressurização do ar em garrafas para aumentar a velocidade da água que gira a turbina até a indução eletromagnética que ocorre dentro de um pequeno motor utilizado para a geração da energia, visualizada pelos alunos através do brilho de um LED preso ao gerador.

Posteriormente será apresentado o seu esquema de construção e uma discussão sobre o uso deste tipo de material em sala de aula, além da apresentação de algumas estratégias de ensino que podem ser elaboradas a partir do uso do modelo.

\section{A Física do modelo}

O modelo apresentado neste trabalho foi concebido para ilustrar o funcionamento de uma usina de transformação de energia que utiliza um gerador eletromecânico e para fomentar as discussões sobre a geração de energia sustentável, tema muito abrangente e que deve estar sempre presente nas aulas de Ciências, sobretudo por causa da sua importância para o desenvolvimento sustentável de qualquer país. Pela simplicidade, outros modelos poderiam ter sido escolhidos, como o caso de uma torre eólica, por exemplo, mas construir um modelo portátil 
que ilustrasse o tipo de usina mais utilizado no país poderia ser muito mais proveitoso para as discussões posteriores em sala de aula.

As discussões feitas tanto na construção quanto na utilização deste modelo em sala de aula podem ser elaboradas em torno de observações que produzem dados qualitativos, ou seja, ilustrem bem os conceitos físicos envolvidos no funcionamento do modelo, além das relações entre as grandezas físicas envolvidas e a contextualização com as usinas hidroelétricas reais. No entanto, como muitas dessas grandezas podem ser coletadas através de medidas simples, o professor pode trabalhar com os dados quantitativos e fomentar a utilização das equações que regem a Física de uma ou das três partes principais do modelo.

Estas partes principais formam a matriz conceitual do modelo, pois o funcionamento de cada uma delas é de suma importância na dinâmica que controla a geração de energia. A primeira parte forma o sistema que fornece a energia primária para a geração, ou seja, dá velocidade à água para que haja rotação na turbina. Isso acontece quando ar é pressionado em uma garrafa PET com água até a metade. Quando um registro é aberto a água é liberada, passando por um furo de $3 \mathrm{~mm}$ de espessura, que aumenta a velocidade do fluxo de água. A segunda parte é representada pelo recipiente que contém a turbina, cuja transformação de energia cinética de translação da água em energia cinética de rotação das turbinas transmite esse movimento para o gerador, que forma a terceira parte principal do modelo. A seguir será feita uma discussão sobre os conceitos físicos que qualificam e quantificam as três partes do modelo, embora as quantidades não sejam abordadas nesse trabalho.

\section{$1^{a}$ Parte: Sistema de pressurização da água}

Esta parte do modelo representa o início da interação dos alunos com os conceitos iniciais de fluidodinâmica presentes na expulsão da água pelo furo feito no cap (tampa de fim de cano). Nesta etapa da interação os alunos devem observar as relações visíveis entre a velocidade de diminuição da água dentro da garrafa e a sua velocidade de saída no furo, cujo impacto com as pás da turbina geram um torque que a rotaciona. A velocidade de saída da água pelo furo é notada pela velocidade de rotação da turbina.

Ao colocar água até a metade garrafa PET e pressionar o ar para dentro dela, a pressão do gás sobre a lâmina de água aumenta significativamente. Com isso, a água é empurrada com uma força derivada da pressão sobre a área da garrafa, que faz a água escoar com uma velocidade, aumentada quando ela passa do recipiente para o furo. Como as áreas da secção transversal da garrafa e do fur são diferentes mas não insignificantes, as duas equações hidrodinâmicas que regem o movimento da água, com uma boa aproximação são a equação da continuidade (eq. 1) e a equação de Bernoulli (eq. 2), mostradas abaixo (NUSSENZVEIG, 2002).

$$
\begin{gathered}
A_{1} \cdot v_{1}=A_{2} \cdot v_{2} \\
p_{1}+\rho g h_{1}+\frac{\rho v_{1}^{2}}{2}=p_{2}+\rho g h_{2}+\frac{\rho v_{2}^{2}}{2}
\end{gathered}
$$


Da equação (1) temos que:

$$
v_{1}=\frac{A_{2} \cdot v_{2}}{A_{1}}
$$

Esta equação relaciona as áreas de secção transversal da garrafa $\left(\mathrm{A}_{1}\right)$ e do furo feito no tampão $\left(\mathrm{A}_{2}\right)$ com as velocidades da água nos dois elementos (garrafa e furo), resultando em uma relação entre elas. Como a área de secção transversal da garrafa é cerca de 100 vezes maior que do furo, significa que a velocidade de saída da água no furo tem a mesma razão. Substituindo (3) em (2), conhecendo a pressão do ar comprimido na garrafa por um barômetro acoplado na bomba, sabendo que $p_{2}$ é a pressão do ar e considerando que a diferença entre as alturas $\mathrm{h}_{1}$ e $\mathrm{h}_{2}$ é muito pequena, que faz o trabalho do peso da coluna de água no recipiente ficar insignificante, com a equação (4) abaixo pode ser determinada a velocidade de saída da água no furo.

$$
p_{1}+\frac{\rho A_{2}^{2} v_{2}^{2}}{2 A_{1}^{2}}=p_{2}+\frac{\rho v_{2}^{2}}{2}
$$

Como a pressão $\mathrm{p}_{1}$ é maior que a pressão atmosférica denotada por $\mathrm{p}_{2}$, ela acaba empurrando toda a água da garrafa diminuindo pouco essa pressão, fazendo com que a velocidade de saída da água também não diminua tanto. Nesta parte os alunos devem identificar quais grandezas físicas estão envolvidas no processo e as suas variações, ou seja, deve perceber que quanto maior a pressão interna do ar na garrafa, maior será a força que empurrará a interface ar/água, aumentando tanto a velocidade de esvaziamento da garrafa quanto a velocidade da água que sairá do furo e, assim, maior será a rotação da turbina.

Realizando um tratamento algébrico nesta equação, pode-se determinar a velocidade de saída do jato de água, isolando $v_{2}$, o que resulta em:

$$
v_{2}^{2}=V^{2}=A_{1} \cdot \frac{2 \cdot\left(p_{2}-p_{1}\right)}{\rho \cdot\left(A_{2}^{2}-A_{1}^{2}\right)}
$$

\section{$2^{\mathrm{a}}$ Parte: Mecânica rotacional na turbina}

No funcionamento do modelo a turbina é a parte que conecta a mecânica de fluidos à mecânica de rotação que aciona o gerador. A água expelida pelo mecanismo de pressurização sai com uma velocidade imposta pela redução da equação (4) e, ao colidir com as pás da turbina, imprime uma força $\mathbf{F}$ ortogonal à pá, resultando em um torque quase instantâneo, que causa uma aceleração angular de mesmo modo à turbina, que a faz girar no mesmo sentido da força impressa, como mostra a Fig. 1. Esta força sendo constante é capaz de vencer a inércia rotacional da turbina e as forças resistivas de atrito que agem nos mancais do seu eixo. 


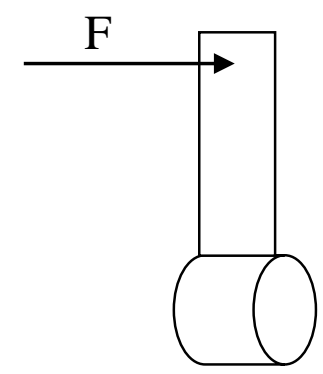

Fig. 1 - Vetor de força impressa na pá da turbina.

Para fins de compreensão dos conceitos e das grandezas físicas envolvidas neste sistema rotacional, pode-se fazer uma abordagem que considera a conservação de energia mecânica relacionando a energia cinética translacional de uma porção de água de massa $\Delta \mathrm{m}$, cuja velocidade é a mesma determinada na equação (5), com a energia cinética rotacional da turbina, resultando em:

$$
\frac{\Delta m \cdot V^{2}}{2}=\frac{I \cdot \omega^{2}}{2}
$$

sendo I o momento de inércia da turbina e $\boldsymbol{\omega}$ a velocidade angular impressa pela força que a massa de água $\Delta \mathbf{m}$ faz sobre a pá da turbina (HALLIDAY, 2012). Pode-se supor também que a velocidade angular da turbina seja alcançada quase que instantaneamente a partir de uma aceleração angular que decai da mesma forma a zero, o que faz com que a velocidade angular seja constante a partir de um intervalo de tempo $\Delta \mathbf{t}$ muito pequeno. Assim, correlacionando estas grandezas citadas, pode-se obter a seguinte equação, a partir de (6):

$$
\frac{2 \cdot A_{1} \cdot \Delta m \cdot\left(p_{2}-p_{1}\right)}{\rho \cdot\left(A_{2}^{2}-A_{1}^{2}\right)}=I . \omega^{2}
$$

Apesar de se ter desconsiderado as forças resistivas que atuam no sistema rotativo (atrito do eixo com os mancais, carga elétrica útil ligada ao gerador que imprime uma força resistente à sua rotação) é necessário que se faça uma discussão com os alunos para que eles compreendam que em um sistema real, as equações não são tão ideais quanto estas. Assim, como não se conhece nem as forças de atrito nem a carga elétrica útil envolvida, basta haver uma discussão apenas qualitativa destes fatores, visto que a velocidade angular também é desconhecida, mas pode ser determinada a partir de uma aproximação, da velocidade do jato de água com a velocidade tangencial do ponto de ação da força imposta pela água nas pás da turbina, uma vez que as outras grandezas físicas são conhecidas. 


\section{$3^{\text {a }}$ Parte: $O$ gerador eletromecânico}

Os conhecimentos básicos dos alunos para a compreensão do funcionamento de um gerador desse tipo se limitam à propriedade do campo magnético de um ímã e da indução eletromagnética causada pela variação temporal do fluxo do campo em uma bobina.

Sabe-se que o módulo do campo magnético de um ímã comum diminui à medida que a distância a ele aumenta. Representam-se as linhas de indução do campo magnético com linhas fechadas, onde os vetores do campo têm módulo maior próximo ao ímã e são tangentes às linhas, como mostrado na Fig. 2.

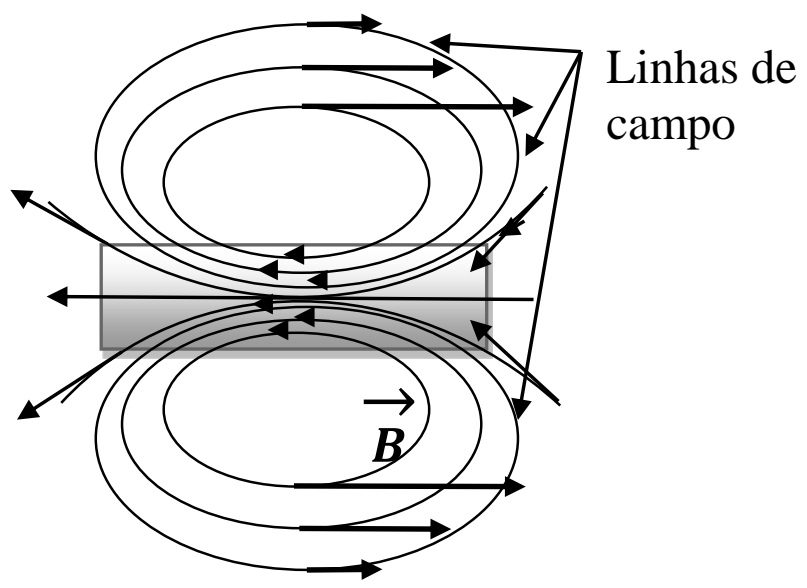

Fig. 2 - Esquema das linhas de indução magnética de um ímã permanente.

Distanciando ou aproximando um ímã de uma região, existe ali uma variação no módulo do campo magnético, aumentando quando ele se aproxima e diminuindo quando se afasta. Fixando-se uma espira nesta região, os vetores do campo magnético passam pela área da espira, gerando um fluxo de campo magnético, que é dado pela expressão (MAXIMO; ALVARENGA, 2012):

$$
\Phi_{B}=B \cdot A \cdot \cos \theta
$$

no qual $\boldsymbol{B}$ é o valor do módulo do campo magnético na espira, $\boldsymbol{A}$ a área da espira e $\boldsymbol{\theta}$ o ângulo entre a linha de indução do campo e a reta normal à área da espira. Considerando que assim como o campo magnético diminui ou aumenta à medida em que a sua distância varia, existe também uma variação neste fluxo do campo magnético que passa pela espira, em um determinado tempo.

Segundo a Lei de Faraday, a variação temporal do fluxo do campo magnético dentro da espira gera uma força eletromotriz, ou seja, faz aparecer um campo elétrico dentro do fio, que acelera os elétrons livres, iniciando assim uma corrente elétrica. Matematicamente (HALLIDAY, 2002): 


$$
\varepsilon=-\frac{\Delta \Phi_{B}}{\Delta t}
$$

Assim, considerando-se uma bobina com $\mathbf{N}$ espiras, existirá um acréscimo na força eletromotriz gerada por este fenômeno, que é dado pela equação:

$$
\varepsilon=-N \cdot \frac{\Delta \Phi_{B}}{\Delta t}
$$

Essa lei é usada para a confecção dos geradores de energia elétrica mais simples, que utilizam um ímã para o fornecimento do campo magnético e uma bobina onde as linhas do campo perpassam, gerando o fluxo do campo (HEWITT, 2004). Para a variação temporal do fluxo pode-se:

1. Girar o ímã, fazendo com que os polos se alternem e exista aí uma variação no fluxo do campo magnético na bobina, que neste caso estará fixa;

2. Girar a bobina, fazendo com que a reta normal à área da bobina se alterne, alternando assim o fluxo do campo magnético formado pelo ímã, que neste caso estará fixo.

O motor de corrente contínua funciona como um gerador eletromecânico, pois possui todos os elementos principais que o constitui (PIETROCOLA et al, 2010). Dois ímãs semicilíndricos fornecem um campo magnético estático no centro do motor, onde o rotor, constituído de várias bobinas, gira fazendo a área útil das bobinas variar, causando uma variação temporal do fluxo do campo magnético - força eletromotriz induzida.

\section{O modelo}

O modelo foi feito em quatro etapas. A primeira é a turbina, a segunda o suporte e as garrafas para pressurização da água, a terceira o regulador de fluxo e a quarta o gerador eletromecânico, cujas montagens são explicadas passo-a-passo a seguir.

\section{Turbina}

Materiais:

- 2 pedaços de tábua de $8 \mathrm{~cm}$ por $20 \mathrm{~cm}$, com espessura de $1,5 \mathrm{~cm}$.

- 1 pedaço de tábua de $8 \mathrm{~cm}$ por $13 \mathrm{~cm}$, com espessura de 1,5 cm (ambos para o suporte da cúpula da turbina).

- 1 garrafa PET de 5 litros (cilíndrica, utilizada para envasamento de água mineral, para a cúpula da turbina).

- 2 cilindros de madeira leve (geralmente pinus) de $6 \mathrm{~cm}$ de diâmetro por $5 \mathrm{~cm}$ de altura (suporte das pás da turbina).

- Réguas de plástico (pás da turbina)

- $1 \mathrm{~m}$ de tubo ou tarugo de alumínio ou latão, com 4 mm de espessura (eixo da turbina, melhor que seja de alumínio ou um plástico mais resistente, pois são mais leves). 
- Furadeira, serra, uma morsa, colas (dos tipos epóxi e à base de cianoacrilato), rebites e parafusos para fixação.

Com uma broca da mesma espessura do material utilizado para o eixo, fura-se o centro dos dois cilindros de madeira, tomando o cuidado de furar exatamente no centro. Para esta ação pode ser necessária a utilização de um torno mecânico ou uma furadeira de bancada. $\mathrm{O}$ cilindro de madeira é preso na morsa para fazer oito cortes diametralmente opostos para a fixação das réguas (pás da turbina), como ilustra a Fig. 3.

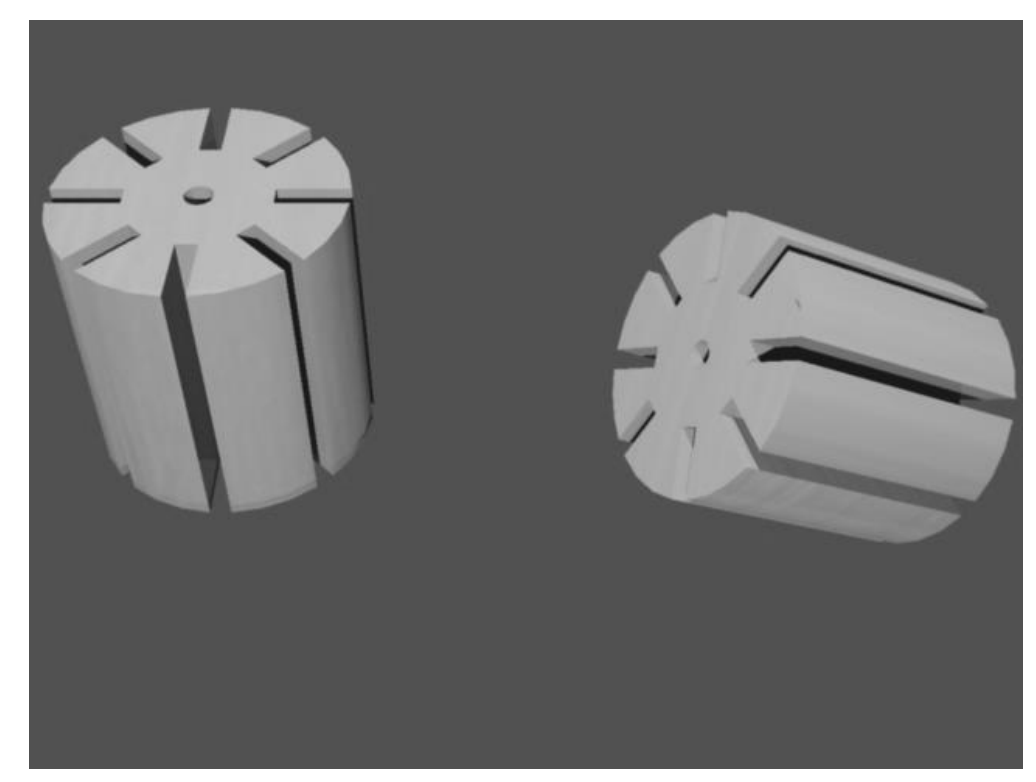

Fig. 3 - Cilindros com os furos e cortes para inserção das pás da turbina.

O diâmetro da turbina deve ser ligeiramente menor que o cilindro da garrafa, para que gire livremente sem colidir com as paredes do recipiente. Algumas garrafas deste tipo têm face da base quadrada, contendo aproximadamente a mesma distância entre os lados, o que significa que deve-se medir primeiramente o tamanho da base (diâmetro ou lado da base quadrada) para fazer a mesma adaptação das pás da turbina.

As réguas são cortadas, respeitando as medidas do recipiente, e coladas nas ranhuras do cilindro de madeira com cola epóxi. O eixo será encaixado com as hélices das turbinas dentro do recipiente de 5 litros. Uma visão das hélices montadas é mostrada na Fig. 4.

A tampa e o fundo da garrafa de água são furados no centro com uma broca pouco maior que a espessura do eixo (cerca de 4,5 mm). Num dos lados da garrafa é feito um corte retangular de largura de $7 \mathrm{~cm}$ em toda a sua extensão para escoamento da água.

As turbinas são inseridas no recipiente por este corte, a tampa fixada e o eixo passado pelos furos da tampa, das turbinas e do fundo (Fig. 5). Para que seja feita essa montagem, primeiro se inserem as turbinas pelo corte retangular, insere-se o eixo pelo orifício do fundo da garrafa, encaixando as turbinas uma a uma e deslizando-as para o local fixo, passando o eixo 
pela boca da garrafa e encaixando na tampa furada. Foi feito um furo com a furadeira nas turbinas até o eixo e inserido um parafuso em cada um para fixar as turbinas e elas não girarem em falso quando o modelo funcionar.

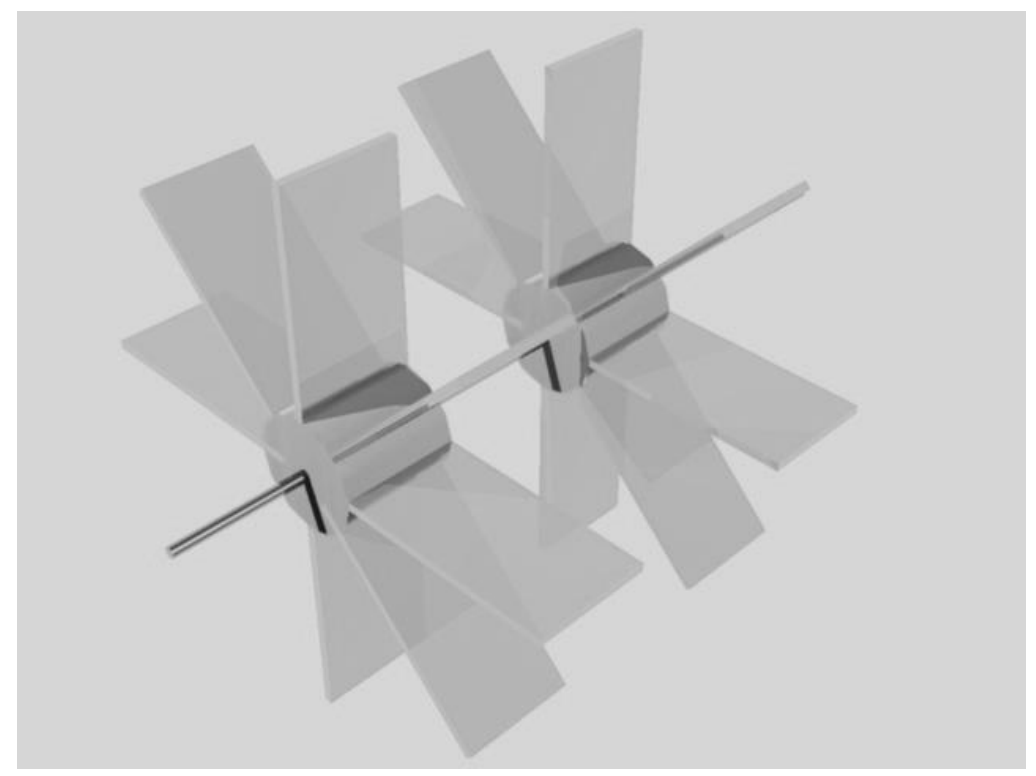

Fig. 4 - Montagem das turbinas.
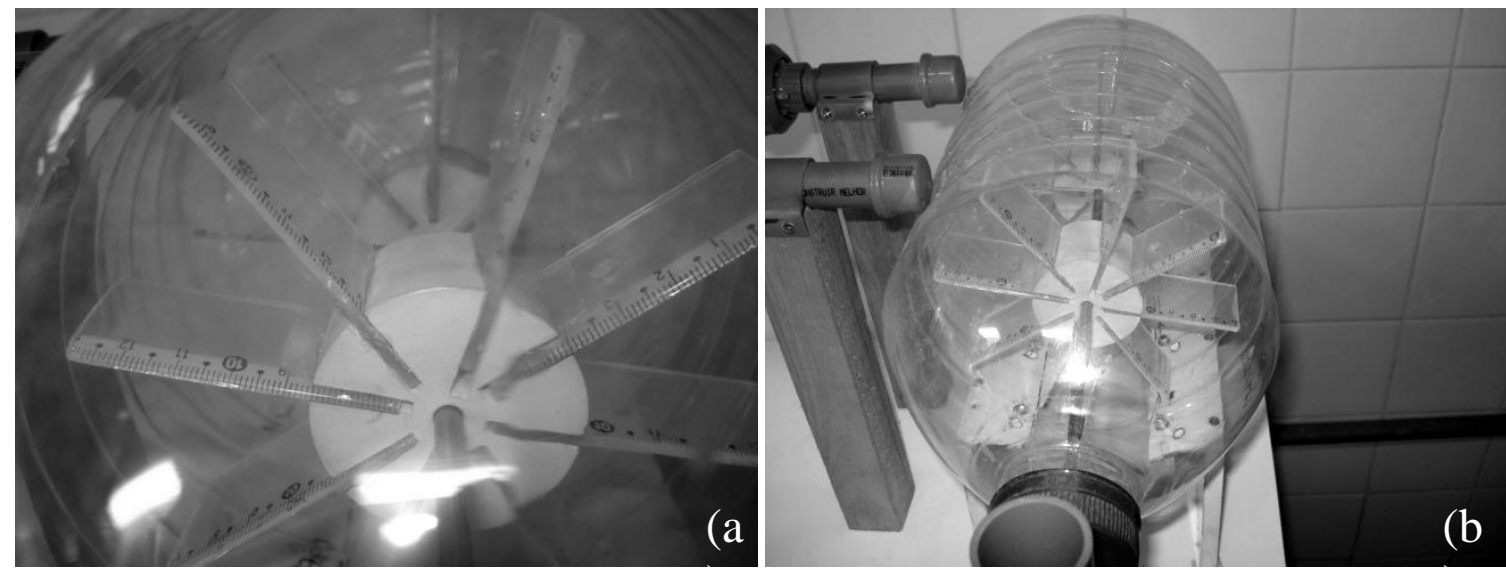

Fig. 5 - Turbinas montadas na garrafa.

O suporte é fixo com parafusos, formando uma caixa retangular, cuja tampa deve ter um corte da mesma largura da abertura da cúpula. Por último é feita a fixação da cúpula da turbina na tampa cortada suporte com os rebites (Fig. 6). Nesta mesma figura observa-se um cano de PVC de $75 \mathrm{~mm}$ de espessura cortado ao meio, utilizado para escoamento da água que sai pela abertura feita na garrafa. 


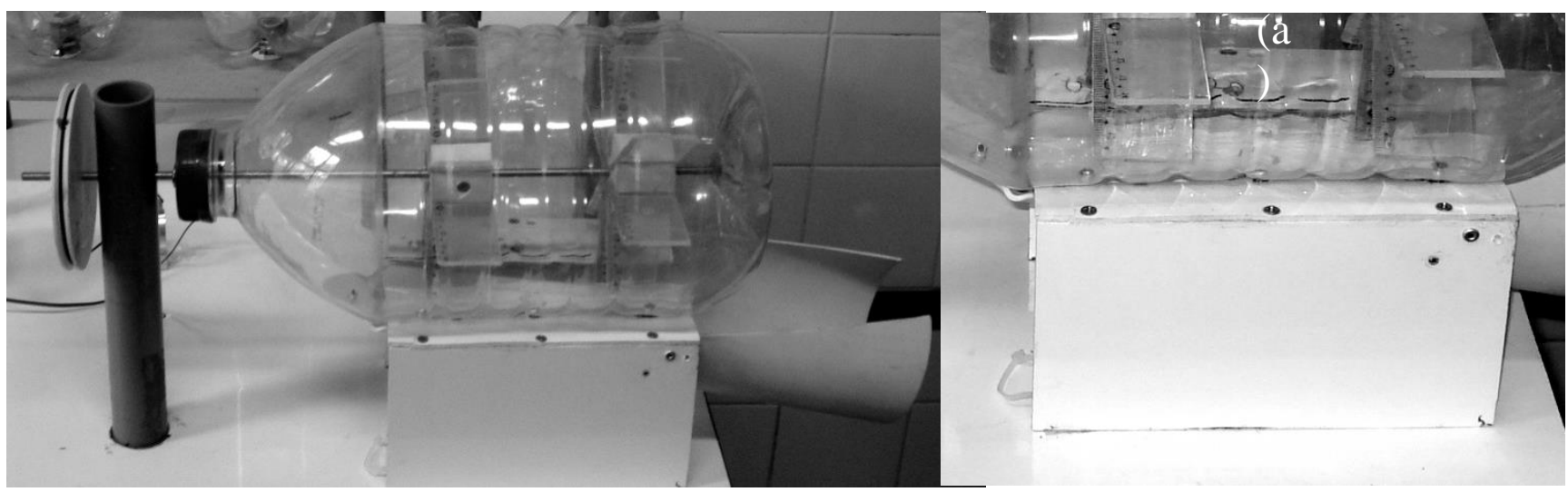

(a)

Fig. 6-Fixação das turbinas.

(b)

\section{Suporte e garrafas de pressurização}

Materiais:

- 4 pedaços de cano de $25 \mathrm{~mm}$, com tamanho de $25 \mathrm{~cm}$ cada (colunas para o suporte das garrafas)

- 2 pedaços de tábua de $3 \mathrm{~mm}$ de espessura, tamanhos $25 \mathrm{~cm} \mathrm{X} 15 \mathrm{~cm}$ (suportes)

- 2 garrafas PET de 2 litros (pressurizadores)

- 2 bicos de pneu de carro com válvula

- 2 conectores de mangueira de jardim

- furadeira, arco de serra, broca chata de $25 \mathrm{~mm}$ e cola para fixação

A preparação das garrafas consiste apenas em furar as tampas na mesma espessura do bico do pneu e encaixá-lo. No fundo de cada garrafa fazer um furo da mesma espessura do bico do conector da torneira. Introduzir o conector pelo gargalo da garrafa, guiando o bico com um arame até o fundo. Ao passar o conector pelo furo, vedar com cola tipo epóxi, como mostra a Fig. 7.

Colocar e vedar o conector do bico da mangueira no fundo da garrafa pode ser trabalhoso, mas a ordem dos conectores pode ser invertida, colocando-se o bico da mangueira na tampa e o bico do pneu no fundo da garrafa PET. O mais importante é não se esquecer de vedar os dois elementos nas suas conexões com a garrafa, para que não haja vazamentos de água pressurizada.

Para o suporte, faz-se um corte com serrote a $5 \mathrm{~cm}$ de uma das pontas e outro de mesma profundidade a $20 \mathrm{~cm}$ de cada um dos canos, onde se encaixarão as quinas das tábuas. Numa das tábuas devem ser feitos dois furos circulares com $10 \mathrm{~cm}$ de diâmetro para o encaixe da garrafa, e na outra dois furos de $25 \mathrm{~mm}$ de diâmetro. É importante que ao montar, os furos estejam alinhados, como mostra a Fig. 8. 


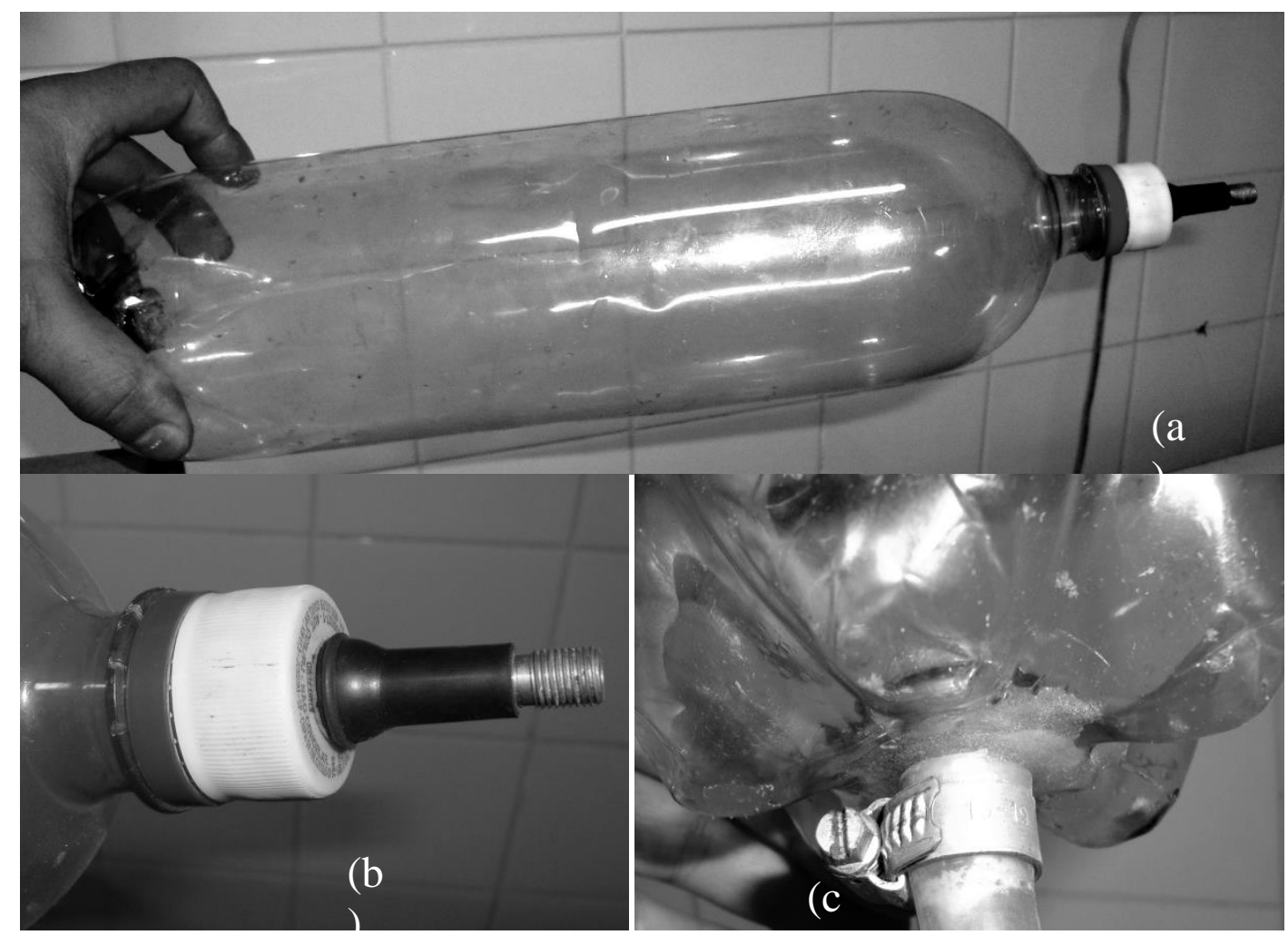

Fig. 7 - Montagem do sistema de pressurização.
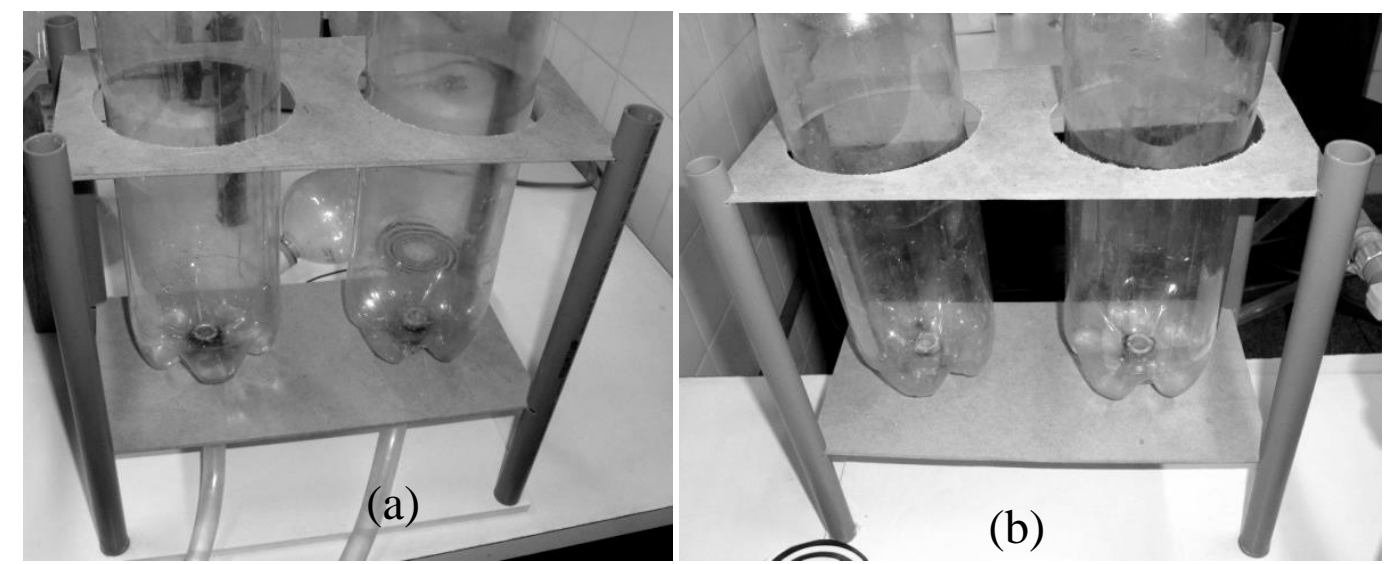

Fig. 8 - Suporte do sistema de pressurização montado.

As garrafas são encaixadas com o conector para baixo, onde são presas mangueiras de PVC com braçadeiras, como mostra a Fig. 7. As outras pontas destas mangueiras serão presas ao circuito regulador de fluxo.

\section{Circuito regulador de fluxo}

Materiais:

- $50 \mathrm{~cm}$ de cano de PVC de $20 \mathrm{~mm}$.

- 2 registros comuns de PVC, com entrada e saída de $20 \mathrm{~mm}$. 
- 2 luvas cola-rosca externa de $20 \mathrm{~mm}$.

- 2 caps (tampões de cano) de $20 \mathrm{~mm}$ - cola.

- 2 pedaços de madeira com $21 \mathrm{~cm}$ de comprimento, $3 \mathrm{~cm} \mathrm{X} 3 \mathrm{~cm}$ de base.

- 2 pedaços de $3 \mathrm{~cm}$ de cano de PVC, com $25 \mathrm{~mm}$.

- parafusos, cola de cano e um isqueiro ou pequeno maçarico para aquecer o cano.

Para a construção do regulador, foi colado um pedaço de $2 \mathrm{~cm}$ de cano de $20 \mathrm{~mm}$ na entrada do registro, que serviu para o encaixe e cola da luva, onde foi presa a outra ponta da mangueira. Na saída do registro foi colado outro pedaço de cano de $20 \mathrm{~mm}$ com $9 \mathrm{~cm}$ de comprimento, onde o cap foi peso com cola na outra ponta.

Foi feito em uma das pontas da madeira do suporte um rebaixo circular com uma serra copo da mesma espessura do cano $(20 \mathrm{~mm})$ para o seu encaixe. O cano de escape da água (com o cap colado) foi preso ao suporte com os pedaços de $3 \mathrm{~cm}$ do cano de $25 \mathrm{~mm}$, nos quais foi feito um corte com o arco de serra, abertos e moldados com uma chama para que tomassem a forma do cano sobre o suporte, como mostra a Fig. 9a, os quais podem ser substituídos por braçadeiras de eletroduto de PVC de $20 \mathrm{~mm}$, facilmente encontradas no mercado. Foram feitos furos no centro dos caps para o escoamento da água, que impulsiona as turbinas, como mostrado no detalhe da Fig. $9 b$.

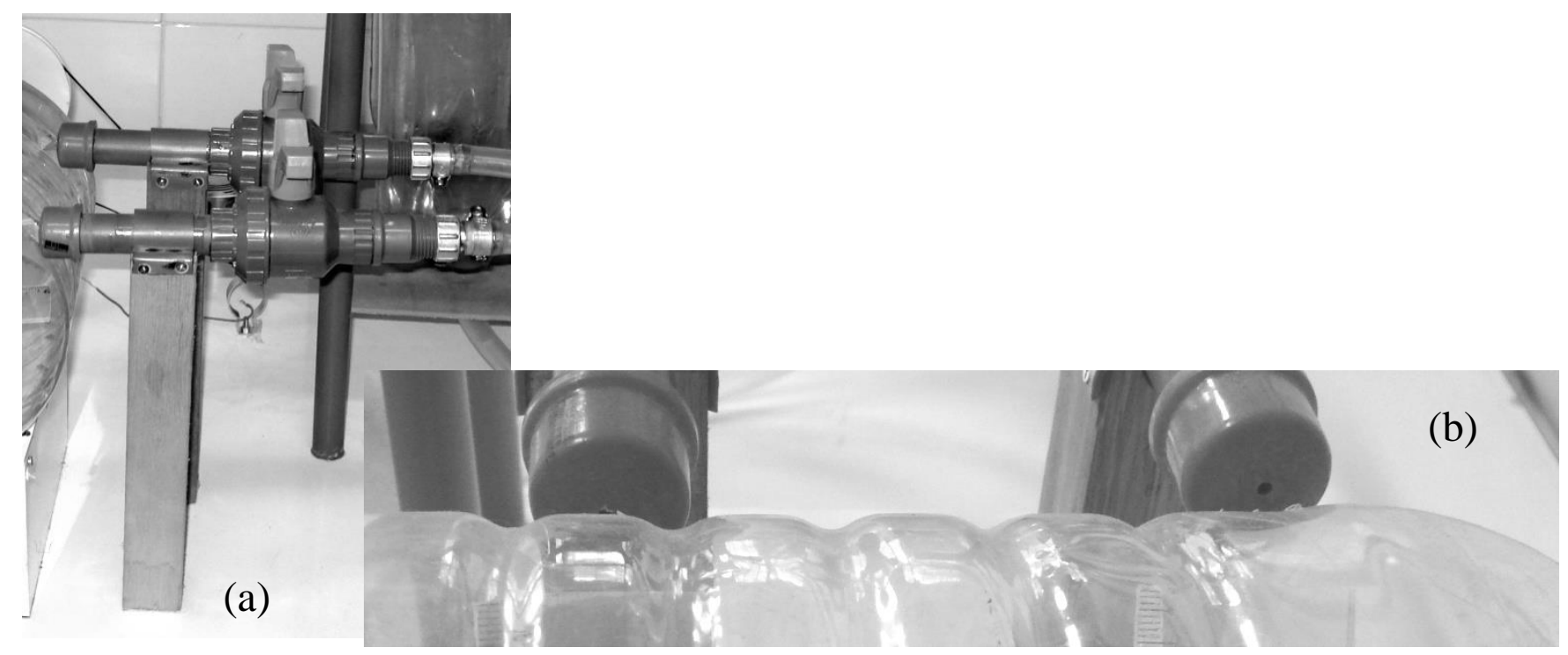

Fig. 9 - (a) Canos com o registro. (b) Caps furados.

\section{Gerador eletromecânico}

Materiais:

- 1 motor de corrente contínua (que pode ser tirado de um carrinho de brinquedo)

- 1 polia com $10 \mathrm{~cm}$ de diâmetro.

- 1 polia com $1 \mathrm{~cm}$ de diâmetro.

- 1 correia de borracha (pode ser utilizada uma liga de látex) 
A polia pode ser feita torneando uma peça de PVC ou utilizando dois CDs, colados lado a lado com outra placa circular mais espessa e de diâmetro menor no centro, como um sanduiche. Foi feito um furo central da mesma espessura que o eixo da turbina, para que a polia se encaixe com certa precisão, minimizando as trepidações quando for girada.

O motor de corrente contínua, utilizado aqui como o gerador de energia, é preso por uma presilha de cano, fixada na base. No eixo do motor é fixada a polia menor. É importante observar o alinhamento entre as polias para que a correia não escape no funcionamento. A montagem pode ser observada na Fig. 10 a.

Para fixar as partes na base, são utilizados parafusos colocados de baixo para cima, e a montagem completa deve ser feita como ilustra a Fig. 10 b.

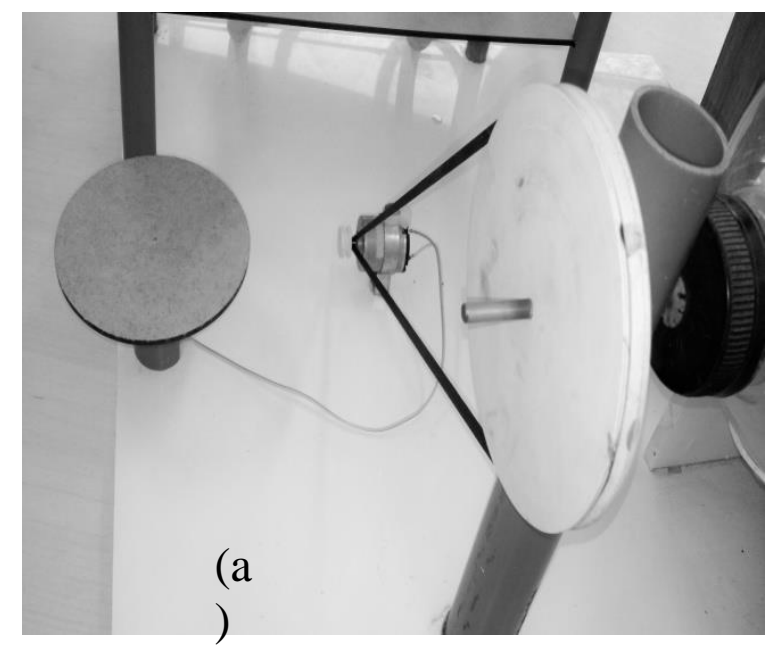

Fig. 10: Montagem geral.

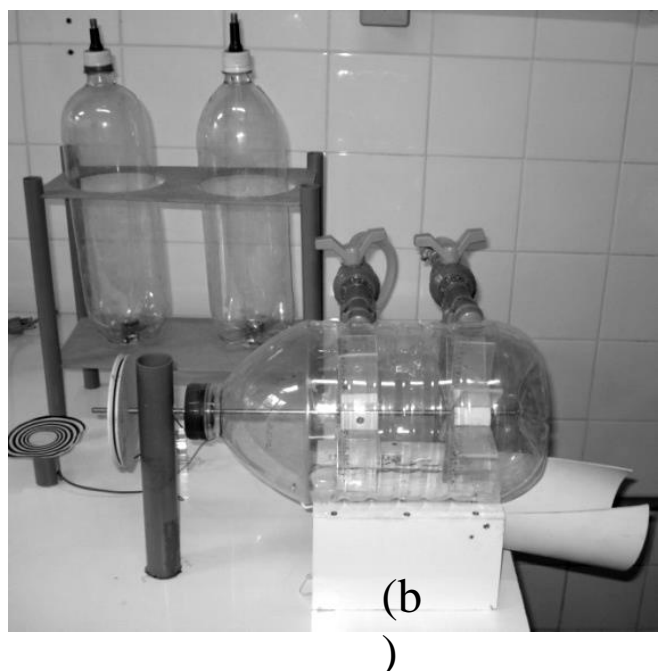

\section{Funcionamento do modelo}

Coloca-se água até a metade de cada uma das garrafas e ar é pressionado com uma bomba comum de encher pneus. Algumas bombas já têm um manômetro incluso, o que facilita a pressurização de ar, que não pode passar de 60 psi em cada garrafa, pois pode desestabilizar a estrutura, fato observado nos testes preliminares, quebrando exatamente no furo realizado para a passagem do conector de mangueira na parte do fundo.

Um dos registros é aberto e a água pressurizada sai, batendo nas pás da turbina encaixada dentro do recipiente grande, o que faz o eixo girar. No fim do eixo foi encaixada a polia maior, ligada com a menor no eixo do pequeno motor por uma correia, fazendo uma redução. Quando a pressão da água de uma garrafa estiver acabando, o outro registro é aberto, liberando a água do outro reservatório, dando continuidade à geração de energia elétrica.

Para visualizar o funcionamento da usina, liga-se aos terminais do motor LED's em configuração de postes ou um motor com um disco de Newton ou outro material preso a ele. Dependendo da criatividade dos alunos que confeccionam o modelo, a visualização pode ser 
feita utilizando-se maquetes de casas ou de uma pequena cidade com as luzes nas casinhas e na rua.

Os alunos das séries finais do Ensino Fundamental e do terceiro no do Ensino Médio podem trabalhar o funcionamento das usinas de transformação de energia elétrica que utilizam um gerador do tipo eletromecânico para gerar energia.

\section{Utilização do modelo como estratégia de ensino-aprendizagem}

Após a observação do funcionamento do modelo pode-se iniciar uma discussão sobre a forma de energia utilizada para girar as pás de uma turbina ligada a um gerador eletromecânico. O modelo envolve, como visto anteriormente, muitos conceitos físicos, desde a mecânica até o eletromagnetismo. A abordagem pode ser conceitual qualitativa ou quantitativa, dependendo do nível de ensino em que o modelo foi utilizado. Uma estratégia interessante para a utilização do modelo é fazer os alunos relacionarem, após a observação do funcionamento e alguma pesquisa, o modelo com uma usina hidroelétrica real, comparando a função dos elementos principais das usinas e do modelo.

O modelo proposto apresenta analogias com a usina real que devem ser abordadas e exploradas pelo professor, caso da pressurização da água nas garrafas relacionado com a velocidade da água nas turbinas das usinas hidroelétricas, causadas pela pressão hidrostática ou da semelhança das turbinas construídas no modelo com as rodas d’água e as turbinas reais das usinas. Estas analogias são importantes no Ensino de Física e de Ciências porque partem de algumas ações conhecidas dos alunos, seja por terem conhecido em veículos de comunicação ou por terem observado no funcionamento do modelo.

Outra discussão que pode ser feita é sobre a geração de energia no país, que no ano de 2015 passou por problemas causados pela falta de chuvas nas represas, o que forçou o governo a colocar as usinas termoelétricas em operação, causando um aumento nas tarifas de energia com a chamada "bandeira vermelha". A compreensão dos impactos sociais causados por estes aumentos sucessivos de tarifa é um assunto que pode ser abordado em discussões transdisciplinares, com a participação de professores das áreas de Ciências Humanas, caso da Sociologia, Geografia e Filosofia.

Segundo Teixeira (2007), a discussão de impactos sociais e da aplicação de conhecimento adquirido no ensino básico formal, ou seja, dentro da escola, ou na educação em espaços não-formais, como museus e centros de ciência (Afonso, 2001), fazem parte de uma consciência cidadã a ser trabalhada na escola em todos os níveis de Ensino. Se ele tem competências e conhecimentos básicos que o auxiliam na discussão e na tomada de decisões que podem eventualmente mudar sua vida e da sua comunidade, seu nível de letramento científico pode ser considerado significativo (CHASSOT, 2000).

Algumas usinas desse tipo já foram feitas em uma escola estadual da capital de São Paulo com alunos de $3^{\circ}$ ano do Ensino Médio e em uma escola municipal na cidade de Barueri com alunos do $6^{\circ}$ ano do Ensino Fundamental. Em todo o processo de construção e utilização 
dos modelos os alunos fizeram pesquisas para entender por que as partes eram importantes no processo de geração de energia elétrica e a função de cada uma dessas partes quando a usina estivesse funcionando.

Com esse trabalho, houve uma compreensão maior dos processos utilizados para a rotação das turbinas, fomentando as discussões sobre outros tipos de energia utilizados para girar as turbinas, extrapolando o uso do gerados eletromecânico em usinas eólicas, térmicas e até em outras plantas de geração de energia mais experimentais, como as usinas de marés e as que funcionam com a energia das ondas. Assim, boa parte dos alunos saiu das aulas com uma ideia inicial sobre as usinas que queimam combustíveis fósseis ou renováveis para acionar as turbinas e quais os tipos de energia que não eram poluentes do meio ambiente, mas mesmo assim poderiam causar algum tipo de agressão, como o caso da própria hidrelétrica.

$\mathrm{O}$ fato dos alunos construírem a usina com a ajuda dos professores e fazê-la funcionar ajuda na compreensão e na habilidade de planejamento do modelo, além da pesquisa teórica sobre seu funcionamento. No caso deste modelo, os alunos do $3^{\circ}$ ano do Ensino Médio apresentaram para salas de outras séries, levantando dúvidas nos colegas que eles mesmos deveriam responder, o que exigiu deles um conhecimento mais profundo do assunto.

\section{Conclusão}

Neste trabalho a interação dos alunos com um modelo demonstrativo pode ser um início do gosto pela ciência e da conscientização deles com relação não só aos processos de geração e distribuição de energia elétrica de forma sustentável ou ecologicamente correta, mas também ao uso consciente dessa energia. Além disso, discussões em sala de aula com os alunos podem melhorar o seu aprendizado e sua consciência ambiental e cidadã, que atualmente são almejados nos níveis de ensino mencionados.

Com a confecção do modelo eles podem adquirir habilidades talvez antes nem trabalhadas, como as mais simples habilidades manuais, e algumas habilidades cognitivas, principalmente as de planejamento, medidas, observação e concretização das ideias iniciais para a construção do modelo.

Outra discussão pode ser feita sobre o funcionamento do motor de corrente contínua, suas partes básicas e sua utilização não só como motor, mas também como gerador de energia elétrica. Todos os modelos de usina hidroelétrica feitos nas escolas utilizaram o motor para sua confecção, para não encarecer o equipamento, uma vez que foram feitos em escolas públicas com poucos recursos financeiros.

Outro fator que auxilia no aumento do nível de letramento científico dos alunos é o fato dele se tornar o protagonista da sua aprendizagem. As etapas de construção da usina necessitam de várias habilidades específicas naturais da disciplina de Física, como a pesquisa, a aplicação e a compreensão de desenhos, modelos e fenômenos físicos presentes que regem o funcionamento da usina. Com a orientação das pesquisas feitas pelos alunos para a compreensão destes fenômenos, as discussões se tornam muito mais proveitosas, estimulando assuntos 
interdisciplinares, como aspectos ambientais, sociais, econômicos, geográficos, etc. fazendo os alunos tomarem posse desse conhecimento, tornando a aprendizagem mais significativa.

Por fim, a aprendizagem desses conceitos e a sua interligação, trazem informações para as discussões sobre os parâmetros que regem a sustentabilidade energética, o consumo sustentável de energia, a possibilidade de utilização de energias renováveis e o papel social e econômico do uso e da produção desses tipos de energia. Estes parâmetros podem ajudar a melhorar a vida das comunidades escolares, constituídas por pais, alunos, professores e comunidade no entorno das escolas, fazendo trabalhos intensos de conscientização sobre a sua situação econômica e energética, ajudando talvez até na economia destas famílias.

\section{Referências bibliográficas}

AFONSO, A. J. Os lugares da educação. In: Educação formal e informal: espaços e culturas. Portugal, 2001.

CHASSOT, A. Alfabetização Científica: questões e desafios para a educação. São Paulo, Editora Unijuí, 2000.

ENEM. Relatório de desempenho dos alunos em Ciências da Natureza e suas Tecnologias. INEP, 2008.

HALLIDAY, D. R.; WALKER, J. Fundamentos de Física: Mecânica. Rio de Janeiro: Editora LTC, 2012. v. 1.

HALLIDAY, D. R.; WALKER, J. Fundamentos de Física: Eletromagnetismo. Rio de Janeiro: Editora LTC, 2012. v. 3.

HAZEN, R. M.; TREFIL, J. Saber Ciência. São Paulo: Cultura Editores Associados, 1995.

HEWITT, P. Física conceitual. São Paulo: Bookman, 2002.

MÁXIMO, A.; AlVAREnGA, B. Curso de Física. São Paulo: Ed. Scipione, 2012. v. 3.

NUSSENZVEIG, H. M. Física Básica: Fluidos, Oscilações e Ondas e Calor. Rio de Janeiro: Editora Edgadr Blucher, 2002. v. 2.

PIETROCOLA, M.; POGIBIN, A.; ANDRADE, R.; ROMERO, T. R. Coleção Física em Contextos. São Paulo: Editora FTD, 2010. v. 3.

PISA, Program for international students assessment - Relatório de desempenho dos alunos brasileiros. OECD. New York, 2006. Disponível em: <www.oecd.org/document/2/0,3343,en_ 32252351_32236191_39718850_1_1_1_1,00.html>. Acesso em: 24 mar. 2008.

TEIXEIRA, J. N. Categorização do nível de letramento científico dos alunos de Ensino Médio. 2007. Dissertação (Mestrado) - Instituto de Física, Universidade de São Paulo. 